\title{
Clostridium thermocellum DSM 1313 transcriptional responses to redox perturbation
}

Kyle Sander ${ }^{1,2,3}$, Charlotte M. Wilson ${ }^{2,4}$, Miguel Rodriguez Jr. ${ }^{2,4}$, Dawn M. Klingeman ${ }^{2,4}$, Thomas Rydzak ${ }^{2,4}$, Brian H. Davison ${ }^{1,2,4}$ and Steven D. Brown $n^{1,2,4^{*}}$

\begin{abstract}
Background: Clostridium thermocellum is a promising consolidated bioprocessing candidate organism capable of directly converting lignocellulosic biomass to ethanol. Current ethanol yields, productivities, and growth inhibitions are industrial deployment impediments for commodity fuel production by this bacterium. Redox imbalance under certain conditions and in engineered strains may contribute to incomplete substrate utilization and may direct fermentation products to undesirable overflow metabolites. Towards a better understanding of redox metabolism in $C$. thermocellum, we established continuous growth conditions and analyzed global gene expression during addition of two stress chemicals (methyl viologen and hydrogen peroxide) which changed the fermentation redox potential.
\end{abstract}

Results: The addition of methyl viologen to C. thermocellum DSM 1313 chemostat cultures caused an increase in ethanol and lactate yields. A lower fermenter redox potential was observed in response to methyl viologen exposure, which correlated with a decrease in cell yield and significant differential expression of 123 genes $\left(\log _{2}>1.5\right.$ or $\log _{2}<-1.5$, with a $5 \%$ false discovery rate). Expression levels decreased in four main redox-active systems during methyl viologen exposure; the [NiFe] hydrogenase, sulfate transport and metabolism, ammonia assimilation (GSGOGAT), and porphyrin/siroheme biosynthesis. Genes encoding sulfate transport and reduction and porphyrin/ siroheme biosynthesis are co-located immediately downstream of a putative iscR regulatory gene, which may be a cis-regulatory element controlling expression of these genes. Other genes showing differential expression during methyl viologen exposure included transporters and transposases.

Conclusions: The differential expression results from this study support a role for $C$. thermocellum genes for sulfate transport/reduction, glutamate synthase-glutamine synthetase (the GS-GOGAT system), and porphyrin biosynthesis being involved in redox metabolism and homeostasis. This global profiling study provides gene targets for future studies to elucidate the relative contributions of prospective pathways for co-factor pool re-oxidation and C. thermocellum redox homeostasis.

Keywords: Clostridium thermocellum DSM 1313, Microarray, Transcriptomics, Methyl viologen, Chemostat, Redox, Sulfate, GS-GOGAT, Hydrogenase

\section{Background}

Clostridium thermocellum natively expresses enzymes to both deconstruct lignocellulosic biomass and ferment cellulose into ethanol, making it a candidate biocatalyst for consolidated bioprocessing (CBP). C. thermocellum hydrolyzes lignocellulosic biomass rapidly and efficiently

\footnotetext{
*Correspondence: brownsd@ornl.gov

${ }^{2}$ BioEnergy Science Center, Oak Ridge National Laboratory, Oak Ridge, TN 37831, USA

Full list of author information is available at the end of the article
}

using an elaborate enzyme system in the form of free and cell bound multi-enzyme cellulolytic complexes called cellulosomes $[1,2]$. Although its hydrolysis machinery is among the fastest and most effective known [3], its fermentative metabolism results in yields and productivities too low for cost-effective industrial lignocellulosic ethanol production $[2,4]$.

In addition to ethanol, $C$. thermocellum natively produces acetate, lactate, formate, and hydrogen. Efforts to eliminate these undesirable products [5-7], in 
conjunction with metabolic engineering of lignocellulosic substrates, have been met with higher ethanol yields [8]. Another limitation to ethanol yield and productivity is a presumed 'overflow' metabolism by which C. thermocellum makes a number of other products, a phenomenon that seems to be exacerbated when fermentative metabolic pathways that reoxidize redox co-factors are eliminated or when substrate loadings are relatively high [9-11]. C. thermocellum metabolism is affected by the addition of exogenous fermentation products [12] and inhibitor chemicals [13] as well as other environmental perturbations. These responses were seen through altered end-product distributions, $\mathrm{O} / \mathrm{R}$ balances, and inhibited substrate uptake. Further, metabolic changes that originate at the level of sensing and transcription have been observed in response to different physical and chemical perturbations [14-17]. The mechanisms by which $C$. thermocellum senses, regulates, and balances redox status remain poorly understood and a deeper understanding may inform future metabolic engineering efforts. The potential inability of various engineered and wild-type strains to sufficiently reoxidize redox cofactors and possible cellular redox imbalance from overly reduced co-factor pools is an area of biotechnological interest.

Redox metabolism has been studied in many organisms capable of carrying out a variety of redox reactions. One method to examine redox-related metabolism is to observe gene expression responses to an altered redox environment $[18,19]$. Other studies have employed comparative genomics approaches [20], rex regulatory gene deletion studies [21, 22], or high-throughput genetic approaches such as rapid transposon liquid enrichment sequencing (TnLE-seq) under stress conditions [23] to investigate physiological and regulatory responses. Such studies give insights into not only transcriptional responses, but also regulons and signaling responses to such environments. After methyl viologen exposure, Clostridium acetobutylicum showed decreased expression of solvent-producing genes, as well genes involved in sulfate and iron transport, while butanol synthesizing genes showed increased transcription concomitant with a much higher butanol/acetone ratio [19]. Fermentation and metabolite analysis of Clostridium cellulolyticum implicated high $\mathrm{NADH} / \mathrm{NAD}^{+}$ratio, and low pyruvate:ferredoxin oxidoreductase activity causing limited fermentative metabolism and production of overflow products [24, 25]. Hence, studies into redox metabolism have the potential to not only provide fundamental insights but also have potential to advance applied goals.

In this study, we established C. thermocellum steadystate chemostat cultures and investigated redox processes after perturbing environmental conditions through separate additions of two redox-active chemicals; methyl viologen and hydrogen peroxide. Fermentative changes were observed and transcriptional responses of $C$. thermocellum DSM 1313 were studied using DNA microarray analyses.

\section{Results and discussion}

Preliminary batch experiments with methyl viologen

Preliminary batch growth indicated methyl viologen reduction in vivo required viable metabolically active cellular biomass. A change to blue coloration was used as an indication of methyl viologen reduction. To assess methyl viologen reduction, abiotic medium, autoclave killed cells (in medium or water), live growing cells, and cellfree spent medium, each containing $150 \mathrm{mg} / \mathrm{L}$ methyl viologen, were incubated in $C$. thermocellum growth conditions overnight. Blue coloration was only observed after incubation of cells from log-phase or stationaryphase cultures medium containing cellobiose and methyl viologen. Blue coloration was not observed after 5 days of incubation in fresh medium, spent medium, autoclaved cells (in medium or resuspended in water), cells (log phase or stationary phase) resuspended in water, after 5 days of incubation at $55{ }^{\circ} \mathrm{C}$. Preliminary batch fermentations were conducted to estimate the appropriate methyl viologen concentration to introduce into the carbon-limited chemostats (Additional file 1). A decrease in growth rate of batch cultures was seen in cultures containing initial loadings of methyl viologen of $150 \mathrm{ug} /$ $\mathrm{mL}$ and higher. Consistent with an earlier study [26], an increase in end-point ethanol productivity was observed in cultures containing methyl viologen (Additional file 1) and at a final concentration of $150 \mathrm{mg} / \mathrm{L}$ was used in chemostat studies. Methyl viologen has been shown to inhibit Clostridium butyricum hydrogen production during glycerol fermentation [27]; however, in preliminary $C$. thermocellum cellobiose batch studies specific end-point $\mathrm{H}_{2}$ productivity increased with methyl viologen.

\section{Chemostat response to methyl viologen addition}

Carbon-limited (1.1 g/L cellobiose) chemostat grown cultures $\left(0.1 \mathrm{~h}^{-1}\right)$ were supplied with MTC medium containing methyl viologen (Fig. 1). Time "0" for methyl viologen addition was the point when the feed medium was switched from MTC medium to MTC medium containing methyl viologen $(\sim 88 \mathrm{~h}$ after the experiment began). Addition of methyl viologen to the reactor lowered cell density (as measured by fermenter $\mathrm{OD}_{600}$ ) (Fig. 1). An increase in specific ethanol production was observed concomitant with methyl viologen exposure, lower cell densities, and an approximate $50 \mathrm{mV}$ decrease in redox potential (Figs. 1, 2). Throughout methyl viologen exposure, a total of 123 individual genes were 

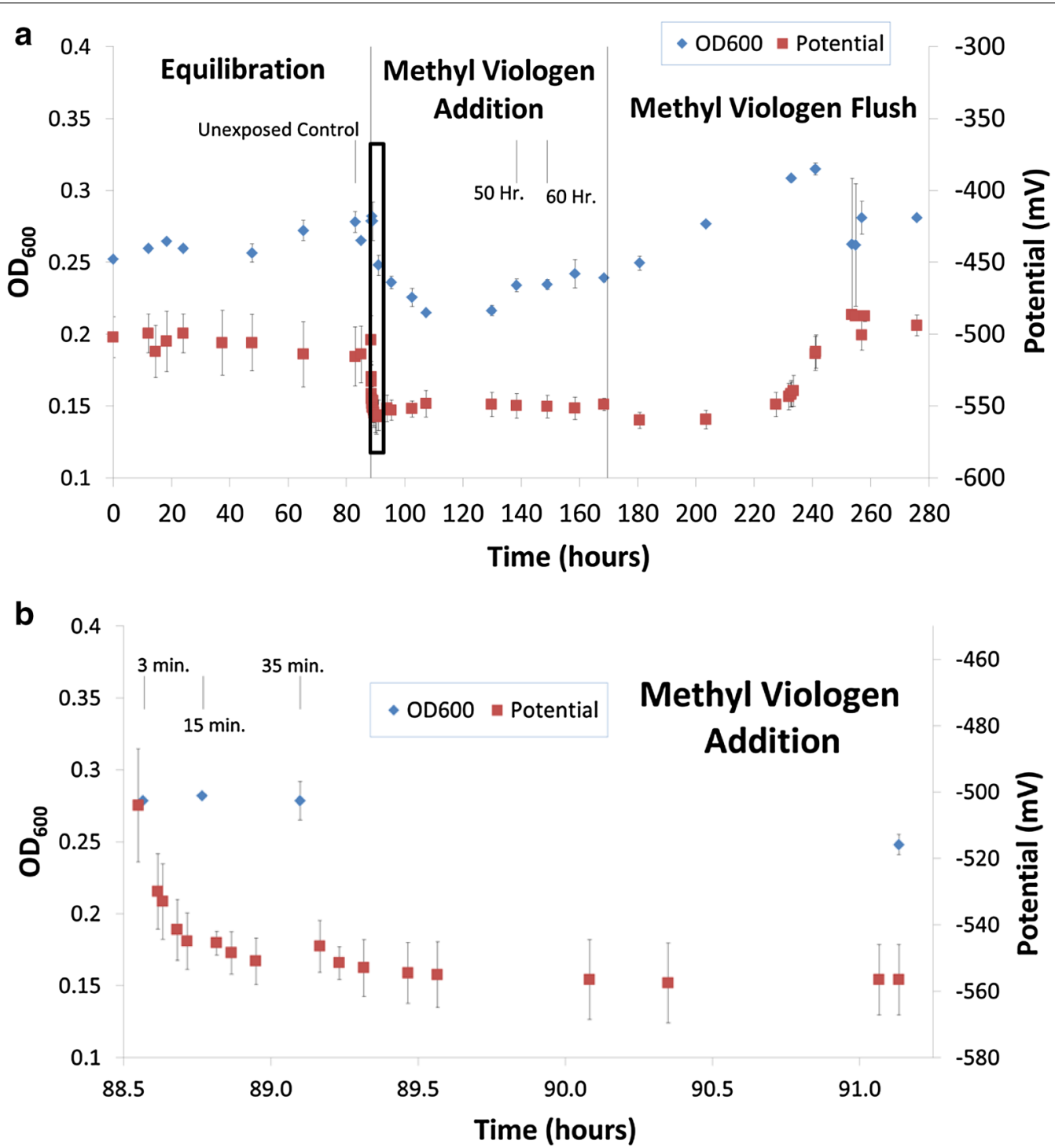

Fig. 1 Chemostat growth and redox potential before, during, and after methyl viologen addition. a Over $280 \mathrm{~h}$ and $\mathbf{b}$ for detailed view of boxed region indicated in panel $\mathbf{a}$

significantly differentially expressed within at least one timepoint (defined as a $\log _{2}$ expression change of $<-1.5$ or $>1.5$ at a false discovery rate $<0.05$ ) (Table 1 ). After methyl viologen was flushed from the system, ethanolspecific productivity returned to pre-exposure levels (Fig. 2) and redox potential measurements returned to pre-exposure redox potential levels (Fig. 1a). Production of acetate remained unchanged before and during methyl viologen addition. Acetate concentration and yield increased after methyl viologen exposure was completed and as methyl viologen was being diluted out of the chemostats. $\mathrm{CO}_{2}$ and hydrogen production was not measured in the open chemostat system. Lactate began to be synthesized after $50 \mathrm{~h}$ of methyl viologen exposure, increasing a specific productivity from 1.85 to $3.55 \mathrm{mM} /$ $\mathrm{OD}_{600}$. Before and throughout methyl viologen addition, all cellobiose substrate was utilized as no residual cellobiose or glucose was detected by HPLC analysis of samples from the fermenters. Specific fermentation products (converted to reflect the amount of carbon in the products; mol C-equivalents/L/OD $\mathrm{OD}_{600}$ ) increased throughout methyl viologen exposure. Ethanol and estimated $\mathrm{CO}_{2}$ (mol C-equivalents/L/OD ${ }_{600}$ ) increased 17.6 and $15.8 \%$, respectively, during $60 \mathrm{~h}$ of increasing methyl viologen exposure (Fig. 2). Increased alcohol concentrations have been observed after adding methyl viologen to cultures 


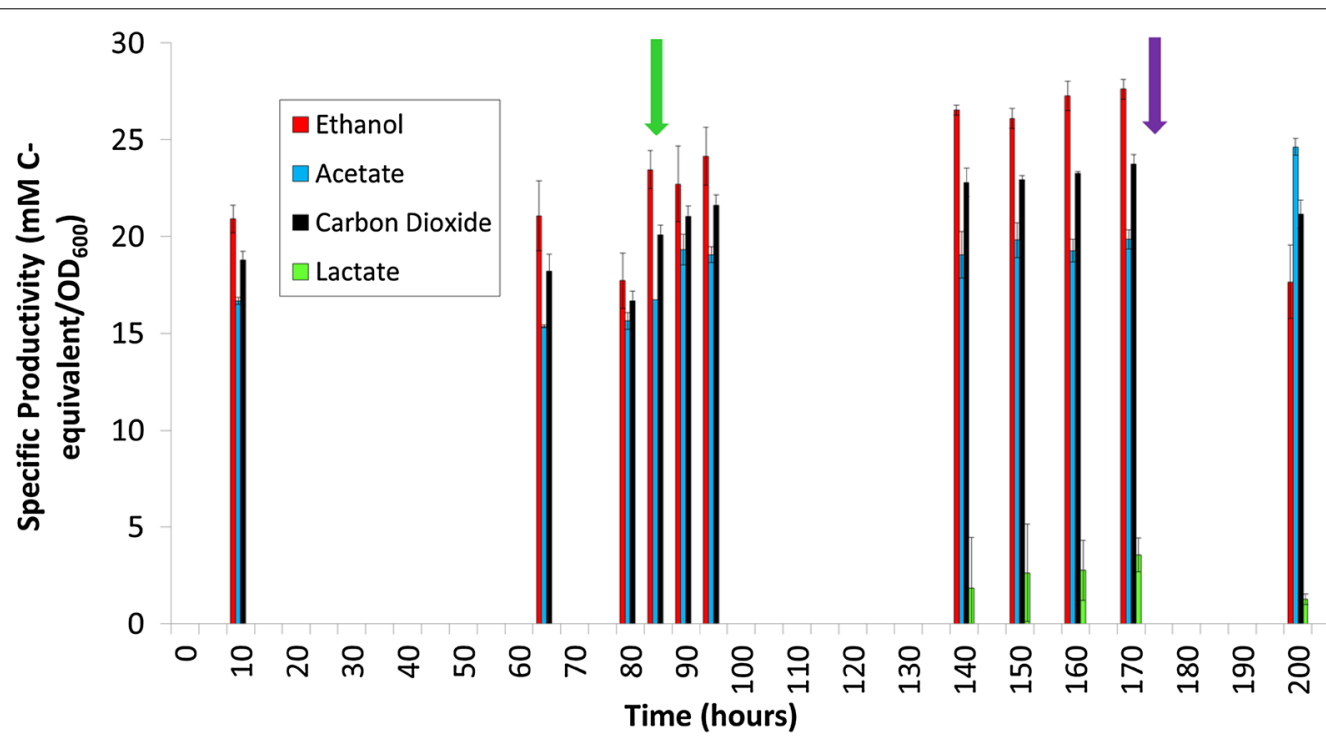

Fig. 2 Fermentation productivity during addition of methyl viologen to chemostat culture. Specific fermentation products (converted to reflect the amount of carbon in the products; $\mathrm{mol} C$-equivalents $/ \mathrm{L} / \mathrm{OD}_{600}$ ) are reported in equivalent carbon mole basis (e.g., $1 \mathrm{~mol}$ ethanol $=2 \mathrm{~mol}$ C-equivalent). Productivity in carbon moles is normalized to $\mathrm{OD}_{600}$ to account for changing cell yields observed across the time culture was exposed to methyl viologen. $\mathrm{CO}_{2}$ productivity is estimated by assuming one mole of $\mathrm{CO}_{2}$ is produced for each mole of ethanol and each mole of acetate produced. Green arrow indicates when methyl viologen exposure began and purple arrow indicates time when methyl viologen flushing from the reactor began

Table 1 Number of genes showing differential expression after beginning methyl viologen addition

\begin{tabular}{|c|c|c|c|c|c|c|c|}
\hline & $3 \mathrm{~min}$ & $15 \mathrm{~min}$ & $35 \mathrm{~min}$ & $7 \mathrm{~h}$ & $14 \mathrm{~h}$ & $50 \mathrm{~h}$ & $60 \mathrm{~h}$ \\
\hline Number of genes up-regulated & 0 & 14 & 1 & 3 & 1 & 21 & 36 \\
\hline Number of genes down-regulated & 20 & 37 & 3 & 8 & 1 & 40 & 47 \\
\hline
\end{tabular}

Significant differential expression was determined to be genes showing $\log _{2}$ fold change relative to untreated controls of $>1.5$ or $<-1.5$ at a $5 \%$ false discovery rate. Significantly differentially expressed genes are highlighted in Additional file 1

of C. acetobutylicum, which was attributed to decreased hydrogen production $[28,29]$. This phenomenon was observed upon methyl viologen addition to C. acetobutylicum cultures and was attributed, in part, to increased transcription of butanol synthesis pathway genes [19]. In this study, transcription of ethanol synthesis genes was not increased significantly.

Global transcriptional analysis suggests that two broad temporal expression patterns are present across genes that showed differential expression in at least one timepoint taken during methyl viologen exposure. Indeed, differential expression at $15 \mathrm{~min}$ was very similar to that sampled at 50 and $60 \mathrm{~h}$. The first pattern observed was decreased expression at $15 \mathrm{~min}$, followed by a return to pre-exposure expression, and finally decreased expression at 50 and $60 \mathrm{~h}$. We interpret this result to suggest an expression response occurring immediately after initial exposure to methyl viologen (while concentrations of methyl viologen in the fermenters are low) followed by a decay of this response to pre-exposure conditions. Beginning at $50 \mathrm{~h}$, expression levels return to levels similar to those seen at $15 \mathrm{~min}$, but do so in a sustained fashion as those levels of expression are largely maintained for another $10 \mathrm{~h}$. It should be mentioned that, by $50 \mathrm{~h}$, concentrations of methyl viologen in the fermenters were estimated to be that of concentrations introduced in the feed carboy; $150 \mathrm{mg} / \mathrm{L}$. We provide the entire significant gene list and focus below on predominant and possibly coordinated systems.

\section{Decreased transcription of redox-active pathways}

Methyl viologen can occur in three reduction states, $\mathrm{MV}^{0}, \mathrm{MV}^{+}$, and $\mathrm{MV}^{2+}$, with the redox potential of the most reduced form being similar to that of electron transfer proteins, flavodoxins and ferredoxins [30, 31]. Methyl viologen can be used in place of natural electron acceptors and oxidoreductase proteins in nitrogenase [32], nitrate reductase [33], and other enzyme assays. In addition to these known enzymatic interactions, methyl viologen has also been shown to interact directly with 
iron-sulfur clusters and, in some cases, degrade them [34]. Fe-S cluster degradation by methyl viologen and other redox-active compounds has been shown to initiate wide-ranging transcriptional changes through induction of the SoxRS transcription factor system [35]. Using mechanisms similar to these, it is conceivable that methyl viologen can interact with redox metabolism indirectly in C. thermocellum and, as such, our experimental system may be capturing transcriptional outcomes of these mechanisms in addition to direct interactions facilitated by enzymes and redox chemistry with redox-active intracellular metabolites.

Four redox-active pathways showed decreased transcription at various timepoints after methyl viologen addition; sulfur transport and assimilation, ATP-dependent GS-GOGAT ammonia assimilation, porphyrin and siroheme biosynthesis, and the [NiFe] Fd-dependent hydrogenase (Figs. 1, 2, 3; Additional file 2). All four systems show decreased transcription at $50 \mathrm{~h}$ (3000 min)$60 \mathrm{~h}$ (3600 min) after methyl viologen addition when estimated methyl viologen concentration in the reactor is greatest and the fermenter redox potential was the lowest. GS-GOGAT and some genes of the [NiFe] system and gene cluster show decreased transcription at three and $15 \mathrm{~min}$ after beginning methyl viologen addition.

\section{Ammonia assimilation}

Previous studies have shown that the malic enzyme is allosterically activated by ammonia for the conversion of malate to pyruvate and it is likely the primary carbon flux

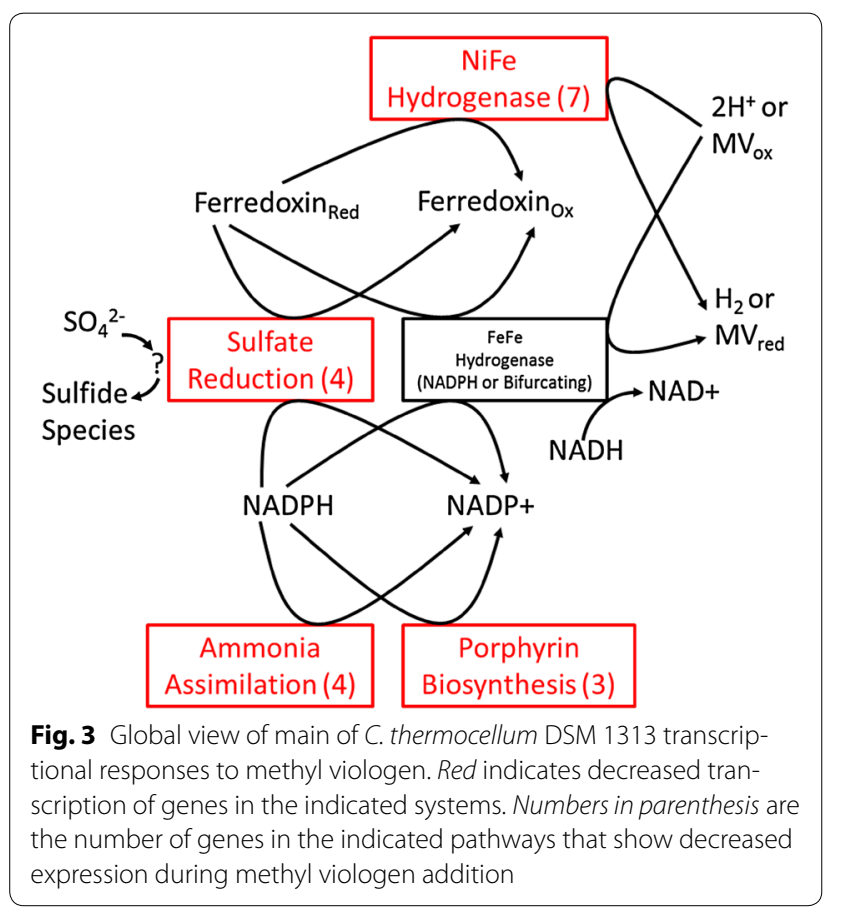

channel under certain growth conditions in C. thermocellum [36]. The putative DSM 1313 malic enzyme gene (Clo1313_1878) showed slightly greater transcript levels after methyl viologen treatment, but not at levels considered significant (Additional file 2). Intracellular metabolites, such as ammonia, and enzymatic activities were not measured as part of present study. We observed genes encoding the GS-GOGAT system showed decreased transcription (Table 2). Both glutamine synthetase (GS) and glutamate synthase (GOGAT) showed decreased expression $\left(\log _{2}\right.$ differential expression of -1.3 to -2.4 relative to untreated controls) at $3 \mathrm{~min}$ and $15 \mathrm{~min}$ and also at 3000 and $3600 \mathrm{~min}\left[\log _{2}\right.$ differential expression of -0.6 to -1.5 relative to untreated controls (Table 2)]. Other genes annotated as glutamine synthetase (Clo1313_2038, Clo1313_2031, and Clo1313_1357) in KEGG and predicted to catalyze the same enzymatic reaction (E.C. 6.3.1.2) showed no differential transcription in this study. One other gene annotated as a glutamate synthase (Clo1313_1849) also did not show any differential transcription in this study. Recent reports suggest that Clo1313_1849 actually encodes the NfnA subunit of NfnAB [13].

Clo1313_2036 and Clo1313_2035, the genes putatively encoding two subunits of glutamate synthase, are part of a gene cluster (Clo1313_2030-Clo1313_2036) that showed similar expression behavior (Additional file 2). Clo1313_2034 is annotated as a 4Fe-4S ferredoxin ironsulfur binding domain-containing protein. Top global protein-BLAST similarity scores are to iron-sulfur cluster containing ferredoxin in other strains of $C$. thermocellum and other Clostridia. Both the GS-GOGAT system and glutamate dehydrogenase are annotated as being NADPH dependent, and to the best of our knowledge, ferredoxindependent GS-GOGAT activity has not been assayed for in C. thermocellum and NADH-dependent GOGAT activity was not found in crude cell lysates of $C$. thermocellum DSM 1273 [37]. Glutamate synthesis from glutamine using glutamate synthase may compete for reductant with other redox processes, including the reduction of methyl viologen. Glutamine biosynthesis also requires glutamate, ATP, and ammonium. Reduced expression of the GSGOGAT system may be the result of added demand for reductant and/or altered cofactor pool states introduced by the presence of oxidized methyl viologen, may reflect lower intracellular ATP levels and/or reflect less cellular demand for glutamine. Such altered states may trigger a transcriptional response towards preserving reductant and/or ATP at the expense of glutamine and glutamate production using this GS-GOGAT system.

Transcriptional regulation of ammonia transport, the GS-GOGAT system, and glutamate dehydrogenase appears to be complex, multi-layered, and varies greatly 
Table 2 Differential expression for GS-GOGAT ammonia and [NiFe] hydrogenase genes

\begin{tabular}{|c|c|c|c|c|c|c|c|c|c|}
\hline \multirow[t]{2}{*}{ Locus tag } & \multirow[t]{2}{*}{ Gene product } & \multirow[t]{2}{*}{ Metabolic function } & \multicolumn{7}{|c|}{$\log _{2}\left(\frac{\text { Expression (Time Exposed) }}{\text { Expression (Unexposed) }}\right)$} \\
\hline & & & $3 \mathrm{~min}$ & $15 \mathrm{~min}$ & $35 \mathrm{~min}$ & $7 \mathrm{~h}$ & $14 \mathrm{~h}$ & $50 \mathrm{~h}$ & $60 \mathrm{~h}$ \\
\hline Clo1313_2303 & Glutamine synthetase catalytic region & GS-GOGAT Ammonia fixation & -2.2 & -2.4 & -0.9 & 1.0 & 1.2 & -1.5 & -1.3 \\
\hline Clo1313_2036 & Glutamine amidotransferase class-II & & -1.3 & -2.1 & -0.4 & 1.6 & 1.5 & -0.6 & -0.7 \\
\hline Clo1313_2035 & Ferredoxin-dependent glutamate synthase & & -2.0 & -2.2 & -0.6 & 1.2 & 1.2 & -1.1 & -0.9 \\
\hline Clo1313_2034 & $\begin{array}{l}\text { 4Fe-4S ferredoxin iron-sulfur binding domain- } \\
\text { containing protein }\end{array}$ & & -2.3 & -2.4 & -0.9 & 0.7 & 0.7 & -1.5 & -1.3 \\
\hline Clo1313_0564 & Hydrogenase expression/formation protein HypE & NiFe hydrogenase & -0.4 & -1.4 & -0.5 & -0.9 & -0.7 & -1.3 & -1.7 \\
\hline Clo1313_0565 & $\begin{array}{l}\text { Hydrogenase expression/formation protein } \\
\text { HypD }\end{array}$ & & -0.4 & -0.6 & -0.1 & -0.3 & -0.3 & -0.7 & -0.9 \\
\hline Clo1313_0566 & Hydrogenase assembly chaperone hypC/hupF & & -0.5 & -0.8 & -0.2 & -0.4 & -0.3 & -0.9 & -1.2 \\
\hline Clo1313_0567 & (NiFe) Hydrogenase maturation protein HypF & & -0.7 & -0.9 & 0.0 & -0.5 & -0.3 & -1.0 & -1.0 \\
\hline Clo1313_0568 & Hydrogenase accessory protein HypB & & -0.1 & -0.5 & 0.5 & 0.0 & 0.0 & -0.4 & -0.9 \\
\hline Clo1313_0569 & Hydrogenase expression/synthesis HypA & & -0.3 & -0.9 & 0.1 & -0.3 & -0.2 & -0.7 & -1.1 \\
\hline Clo1313_0570 & $\begin{array}{l}\text { 4Fe-4S Ferredoxin iron-sulfur binding domain- } \\
\text { containing protein }\end{array}$ & & -0.4 & -1.2 & 0.2 & -0.2 & -0.2 & -0.8 & -1.3 \\
\hline
\end{tabular}

Values in italics indicate statistical significance using a $5 \%$ false discovery rate

between organisms [38, 39]. A transcriptional regulator of ammonia assimilation characterized in C. acetobutylicum, relies on expression of a $n i t R$ antiterminator protein and an antisense RNA [40]. Clo1313_2030 is annotated as a response regulator receiver and ANTAR domain protein. The Clo1313_2030 gene showed decreased expression mirroring that of the gene cluster containing the genes Clo1313_2030 through Clo1313_2036 and its product may provide an antiterminator role sensitive to ammonia concentrations similar to the one described in C. acetobutylicum. The AmtB and PII proteins contribute to ammonia transport and regulation in different systems [38]. Clo1313_2260 contains putative AmtB and PII domains that are 51 and $81 \%$ similar to $C$. acetobutylicum ATCC 824 CA_C0682 and CA_C0681 at the protein level, respectively. In this study, Clo1313_2260 was not significantly differentially expressed.

Glutamate dehydrogenase (Clo1313_1847) catalyzes an alternative mechanism for synthesizing glutamate and assimilating ammonia and glutamate dehydrogenase (Clo1313_1847) was not differentially expressed in this study. Glutamate dehydrogenase activity was shown to be much higher than GOGAT in C. thermocellum DSM 1273 extracts, suggesting it is the predominant method for assimilating ammonia and generating glutamate [37]. However, these experiments were conducted at a maximum nitrogen concentration of $18 \mathrm{mM}$, supplied as ammonia and $0.2 \%$ yeast extract. MTC medium used in this experiment contained more inorganic nitrogen in the form of both urea (33.3 $\mathrm{mM}$ ) and ammonia (as ammonium chloride at $28 \mathrm{mM}$ ). The medium used in this experiment and routinely for $C$. thermocellum growth contains a large excess of nitrogen source and it is possible to culture $C$. thermocellum in medium containing less nitrogen [41].

Glutamate is a precursor to many biosynthetic pathways, including the biosynthesis of porphyrin rings. Porphyrin ring biosynthesis also showed decreased transcription upon exposure to methyl viologen. Decreased demand for glutamate or increased availability may have led to decreased transcription of GS-GOGAT. Other putative KEGG pathways using glutamate as a precursor did not show differential expression. By contrast, increased transcription and translation of both glutamine synthetases (Cthe_0196, Cthe_1539) were observed after C. themocellum ethanol stress, which may have been related to metabolite shuttling into carbamoyl-P, a precursor to pyrimidine, arginine and proline biosynthesis [16], or possibly glutamine synthetase and the ammonia assimilation pathways indirectly assist in reoxidizing redox cofactors.

\section{Sulfate transport and metabolism}

Clostridium thermocellum strain ATCC 27405 has genes for and can assimilate sulfate [41]. As in strain ATCC 27405, sulfate transport genes (Clo1313_0114Clo1313_0117) and putative assimilatory sulfate reduction genes (Clo1313_0119, Clo1313_0120, and Clo1313_0124) are co-located on the DSM 1313 chromosome. In this study, these genes show similar expression patterns and lower expression levels under methyl viologen stress with $\log _{2}$ differential expression of -0.9 to -1.6 relative to untreated controls at 3000 and $3600 \mathrm{~min}$ (Table 3), which is consistent with methyl 
viologen-exposed C. acetobutylicum cells [19] and indicates potential similarity in the physiological and regulatory responses between these organisms. Adjacent to sulfur-related genes, the C. thermocellum Clo1313_0107 gene encodes a putative transcriptional regulator IscR [14], and its expression increased following methyl viologen exposure (Table 3). Differential expression profiles for Clo1313_0107 (iscR) and porphyrin biosynthesis genes are similar when exposed to furfural or heat [14]. Further studies to generate and characterize a Clo1313_0107 deletion strain are required to elucidate its possible roles in sulfate uptake and metabolism, stress responses, and gene regulatory networks. Because methyl viologen is a potential alternative electron sink to reoxidize reduced intracellular cofactors, C. thermocellum DSM 1313 could potentially repress genes involved in sulfate transport and reduction when exposed to methyl viologen in response to a decreased need for electron acceptors. Sulfate reduction is also ATP dependent and it may benefit C. thermocellum DSM 1313 energetically to decrease expression and/or activity of this pathway.

\section{Porphyrin biosynthesis}

Many redox-active enzymes are iron-sulfur containing proteins and siroheme is often a necessary redox-active cofactor. The genes Clo1313_0108-Clo1313_0113 putatively encode for proteins involved in porphyrin/ siroheme biosynthesis and they are adjacent to genes involved in sulfate transport/reduction as well as genes potentially involved in regulation. The Clo1313_0109, Clo1313_0112, and Clo1313_0113 genes show differential expression at $3000 \mathrm{~min}$ after methyl viologen addition $\left(\log _{2}\right.$ differential expression of $-0.7,-1.2$, and -1.2 , respectively, relative to untreated controls), and show the largest differential expression after
$3600 \min \left(\log _{2}\right.$ differential expression of $-1.2,-1.5$, and -1.6 , respectively, relative to untreated controls), when estimated methyl viologen concentration is the highest (Table 3). Three other putative porphyrin biosynthesis genes in this cluster do not meet criteria for significant differential expression. Clo1313_0124 is annotated as nitrite and sulfite reductase, predicted to contain an iron-sulfur/siroheme binding site, and also shows decreased transcription under methyl viologen exposure. Clo1313_0124 is annotated to be ferredoxin dependent. Expression of Clo1313_0109 was shown to increase upon exposure to Populus hydrolysate [17] and decreased expression 10, 30, and 60 min following exposure to increased ethanol concentration [16], which suggests, along with results from this study, that transcription of genes responsible for porphyrin biosynthesis is sensitive to cellular redox potential and/or the redox potential of the fermentation environment. With methyl viologen potentially providing an extra sink for cellular reductant through a process mediated by hydrogenases or occurring directly, there may be less overall demand for these proteins mediating redox reactions. Unbound heme and some of the metabolic intermediates of the tetrapyrrole biosynthesis pathway are known to be cytotoxic and can be recycled [42]. Pseudomonas aeruginosa appears to regulate early stages of heme biosynthesis in accordance with growth state and overall need for heme enzyme cofactors [43]. Many microorganisms have been shown to limit the amount of accumulated 5-aminolenulevulenate [42], suggesting it may be particularly cytotoxic and/or the precursor to a rate-limiting step in tetrapyrrole biosynthesis. Thus, it may be advantageous for $C$. thermocellum DSM 1313 to regulate this pathway and Clo1313_0107 may play a role.

Table 3 Differential expression information for genes Clo1313_0107 through Clo1313_0124

\begin{tabular}{|c|c|c|c|c|c|c|c|c|c|}
\hline \multirow[t]{2}{*}{ Locus tag } & \multirow[t]{2}{*}{ Gene product } & \multirow[t]{2}{*}{ Metabolic function } & \multicolumn{7}{|c|}{$\log _{2}\left(\frac{\text { Expression (Time Exposed) }}{\text { Expression (Unexposed) }}\right)$} \\
\hline & & & $3 \mathrm{~min}$ & $15 \mathrm{~min}$ & $35 \mathrm{~min}$ & $7 \mathrm{~h}$ & $14 \mathrm{~h}$ & $50 \mathrm{~h}$ & $60 \mathrm{~h}$ \\
\hline Clo1313_0107 & Transcriptional regulator, Rrf2 family & Putative IscR transcription factor & 1.1 & 0.2 & 2.4 & 2.1 & 1.9 & 1.3 & 1.7 \\
\hline Clo1313_0109 & Precorrin-6X reductase & Porphyrin Biosynthesis & -0.5 & -0.4 & 0.2 & -0.2 & -0.1 & -0.7 & -1.2 \\
\hline Clo1313_0112 & Delta-aminolevulinic acid dehydratase & & -0.8 & -0.5 & -0.1 & -0.5 & -0.3 & -1.2 & -1.5 \\
\hline Clo1313_0113 & Glutamate-1-semialdehyde-2,1-aminomutase & & -0.9 & -0.6 & 0.1 & -0.3 & -0.3 & -1.2 & -1.6 \\
\hline Clo1313_0115 & $\begin{array}{l}\text { Sulfate } A B C \text { transporter, inner membrane } \\
\text { subunit CysT }\end{array}$ & Sulfate ABC transporter & -0.6 & -0.1 & 0.5 & 0.4 & 0.4 & -1.2 & -1.3 \\
\hline Clo1313_0116 & $\begin{array}{l}\text { Sulfate } A B C \text { transporter, inner membrane } \\
\text { subunit CysW }\end{array}$ & & -0.6 & 0.1 & 0.5 & 0.4 & 0.4 & -1.0 & -1.4 \\
\hline Clo1313_0118 & $\begin{array}{l}\text { Adenylylsulfate reductase, thioredoxin } \\
\text { dependent }\end{array}$ & Sulfate reduction & -0.9 & -0.4 & 0.5 & 0.1 & 0.1 & -1.4 & -1.6 \\
\hline Clo1313_0124 & Nitrite and sulfite reductase $4 \mathrm{Fe}-4 \mathrm{~S}$ region & & -1.4 & -0.2 & 0.2 & 0 & -0.1 & -0.9 & -1.5 \\
\hline
\end{tabular}

Values in italics indicate statistical significance using a $5 \%$ false discovery rate 


\section{[NiFe] hydrogenases}

Methyl viologen has been shown to mediate re-oxidation of reduced cellular species through interaction with hydrogenase proteins $[44,45]$. C. thermocellum DSM 1313 encodes four hydrogenases; three [FeFe] hydrogenases and one [NiFe] hydrogenase. No differential expression was observed in genes encoding any of the three $[\mathrm{FeFe}]$ hydrogenase systems in response to methyl viologen exposure. It is thought that two of the three [FeFe] hydrogenases are bifurcating hydrogenases [46], necessarily requiring one mole of $\mathrm{NADH}$ and one mole of reduced ferredoxin to produce one mole of hydrogen. The third [FeFe] hydrogenase is thought to be NADPH dependent. It has been shown that the NADPH-dependent hydrogenase activity was greater than either reduced ferredoxin or NADH-dependent hydrogenase activity $[47,48]$. Further, low amounts of Ech hydrogenase protein was quantified [46] and poor transcription of ech genes [49] was found using reverse transcriptase PCR from $C$. thermocellum. In contrast, we observe all genes in the ech hydrogenase gene cluster to be highly transcribed in the conditions used in this study, based on LOWESS normalized hybridization intensity. All but one of the genes encoding ech, an [NiFe]-containing hydrogenase (Clo1313_0564-Clo1313_0570) show transient initial decreased transcription at 3 and $15 \mathrm{~min}\left(\log _{2}\right.$ differential expression -0.3 to -1.2 , relative to untreated controls) after beginning methyl viologen exposure, followed by a return to unchanged levels of transcription (significant $\log _{2}$ differential expression not less than -0.4 or greater than 0.2 , relative to untreated controls). Expression of this gene cluster again decreased at 3000 and $3600 \mathrm{~min}$ ( $\log _{2}$ differential expression -0.7 to -1.3 , relative to untreated controls) after beginning methyl viologen exposure when the concentration of methyl viologen in the reactor is highest. All genes in this cluster appear to observe this temporal expression behavior (Table 3). It would be interesting to determine whether or not the $[\mathrm{NiFe}]$ hydrogenase is ferredoxin dependent and biochemically characterize its relative contribution to hydrogen metabolism to better understand co-factor re-oxidation capacity and dynamics in C. thermocellum.

Clostridium thermocellum DSM 1313 has been reported to have overflow metabolic pathways, potentially related to overly reduced intracellular conditions and a need to reoxidize redox cofactors $[9,11]$. [NiFe] ech hydrogenase transcription does not appear to be transcriptionally linked to ATP generation or establishing/modulating the proton motive force in C. thermocel$l u m$, as there was no significant differential expression of the ATP synthase genes (Clo1313_2935-Clo1313_2942) observed during addition of methyl viologen to the culture. In different systems [NiFe], hydrogenase is known to be controlled by a number of different mechanisms and responsive to many different environmental and physiological cues, such as $\mathrm{H}_{2}, \mathrm{O}_{2}$, and $\mathrm{CO}$ as well as the FnrT transcription factor $[50,51]$. [NiFe] hydrogenases have also been linked to nitrogenase activity through electron transfer to membrane-bound $\mathrm{Rnf}$ [50]. C. thermocellum encodes genes with putative functions for $\mathrm{N}_{2}$ fixation (Clo1313_2331, Clo1313_2332, and Clo1313_2339). Clo1313_2331 and Clo1313_2339 show significant decreased transcription at $3 \mathrm{~min}$ after methyl viologen addition and differential expression in an equivalent C. thermocellum ATCC 27405 gene, Cthe_1573 (nifH) showed increased expression $240 \mathrm{~min}$ after exogenous ethanol addition to batch culture [16]. C. thermocellum DSM 1237 was reported to show nitrogen-fixing activity in vitro, via reduction of acetylene, though doubt was cast as the activity was not seen to be repressed by added ammonia [37]. C. thermocellum diazotrophic growth was tested and under the conditions assayed nitrogen fixation was not detected [41]. C. thermocellum electron transfer requires greater study.

\section{Transcription differences in other systems Transporters}

Eight annotated transporters found to be significantly differentially expressed during at least one timepoint under methyl viologen treatment. A CorA family transporter annotated as a magnesium transporter showed relatively strong increased transcription at 3000 and $3600 \mathrm{~min}$ after methyl viologen addition. Five transporters annotated as being ATP binding showed decreased transcription at least one timepoint during methyl viologen exposure.

\section{Sporulation}

Clostridium thermocellum strain ATCC 27405 sporulates at low frequencies (maximum $\sim 7 \%$ ) and not under certain conditions such as in response to low carbon or nitrogen environments [52], which confounds global population-based analyses. In this study, three sporulation genes showed significant decreased transcription (false discovery rate $<0.05$ and $\log _{2}$ differential expression less than -1.5 relative to untreated controls); Cthe_3070, Cthe_0044, and Cthe_2948. The initial sporulation developmental stages transcription factor, spoOA (Clo1313_1409), showed significant changes in expression at 3 and 15 min after beginning methyl viologen addition $\left(\log _{2}\right.$ differential expression of 0.4 and -0.8 , respectively). Two of the four histidine kinases (Clo1313_0286 and Clo1313_1973) previously identified as agents of sporulation control [53] showed increased differential transcription at 3000 $\left(\log _{2} 1.1\right.$ and 1.1, respectively) and $3600 \mathrm{~min}\left(\log _{2} 1.0\right.$ and 1.5, respectively) after beginning methyl viologen 
exposure. Clo1313_1973 also showed relatively strong decreased transcription at $3 \mathrm{~min}$ (significant $\log _{2}$ differential expression of -1.5). In addition to spore formation, C. thermocellum (strain ATCC 27405) can develop an L-form morphology which is another non-growth cell state characterized by low metabolic activity with a spherical or pleomorphic morphology [52]. Spores and L-form cells were not observed together in a previous study [52]. Much remains to be elucidated regarding signal-transduction and regulatory cascades controlling these processes.

\section{Transposases and phage-associated gene expression}

Two genes annotated as transposases (Clo1313_0662 and Clo1313_2686) showed increased transcription after $3600 \mathrm{~min}$ (significant $\log _{2}$ differential expression of 1.8 and 1.7, respectively). These two genes appear to be highly transcribed before and during exposure to methyl viologen (LOWESS normalized expression intensity ranged from $\left.\log _{2} 11.4-13.4\right)$. Transposons have been shown to interrupt and inactivate the C. thermocellum cipA genes [54]. C. thermocellum ATCC 27405 transcriptomic studies have shown differential expression for transposases under different growth and stress conditions $[14,16]$. C. thermocellum strains differ in their phage and CRISPR content [55]. Increased expression of genes associated with a putative phage island (Clo1313_2379-Clo1313_2409) was observed in one of two replicate samples taken after exposure to methyl viologen and immediately prior to beginning exposure to $\mathrm{H}_{2} \mathrm{O}_{2}$, after $3600 \mathrm{~min}(60 \mathrm{~h})$ of re-equilibration growth on MTC not amended with either stressor chemical (Additional file 2). The majority of genes from this phage island were found to show significant increased transcription in C. thermocellum ATCC 27405 after 30, 60, and 120 min of exposure to furfural and ethanol, with the largest transcriptional increases coming $30 \mathrm{~min}$ after exposure and dropping gradually at 60 and 120 min for both conditions [14, 16]. This gene region C. thermocellum DSM 1313 does not contain 'att sites' characteristic of functional lysogenic phage, though the closely related $C$. thermocellum ATCC 27405 does [55]. Genes for phosphate transport and regulation are adjacent to recombinase and phage genes in C. thermocellum ATCC 27405, which indicates possible mechanisms for horizontal gene transfer [14]. Observed strain genome differences and differential expression from this and prior studies suggest transposons, bacteriophage, and CRISPR systems may have and may continue to play important roles in C. thermocellum evolution, although the functionality and implications for these systems have only begun to be investigated.

\section{Hydrogen peroxide addition to chemostat culture}

Compared to untreated fermentation redox potential (approximately $-500 \mathrm{mV}$ ), fermenter redox sharply and briefly increased by approximately $100 \mathrm{mV}$ initially and then remained approximately $25 \mathrm{mV}$ higher than the control during prolonged $\mathrm{H}_{2} \mathrm{O}_{2}$ exposure. However, no genes showed significant differential expression $\left(\log _{2}\right.$ fold change $>1.5$ or $<-1.5$ and a $5 \%$ false discovery rate) after chemostat hydrogen peroxide exposure and only a few gene comparisons showed significant differences (below fold threshold) after $3 \mathrm{~min}$ of $\mathrm{H}_{2} \mathrm{O}_{2}$ exposure. There was no apparent change in acetate, ethanol, lactate, or estimated $\mathrm{CO}_{2}$ cell yields (moles C-equivalent/ $\left.\mathrm{OD}_{600}\right)$. Furthermore, addition of $\mathrm{H}_{2} \mathrm{O}_{2}$ under the conditions mentioned previously had no prominent effect on fermenter $\mathrm{OD}_{600}$. Results are shown in Additional file 3.

It is likely the concentration of hydrogen peroxide introduced into the fermenter, though enough to alter the fermentation redox potential was insufficient to induce detectable transcriptional-level changes. The chemostat cultures were metabolically active and in greater densities compared to the preliminary batch screening assays where hydrogen peroxide was added to lag-phase cultures, which may explain the poor transcriptional response for this condition. Redox couples within the cell, such as the GSH/GSSG couple [56], are able to act as redox buffers and provide cells protection against unfavorable environmental redox conditions while not necessarily requiring changes in transcription. It is conceivable that $C$. thermocellum could have used similar systems to modulate the hydrogen peroxide induced redox perturbation it was exposed to in this experiment, instead of systems requiring changes to its transcription profile. Additionally, hydrogen peroxide is a susceptible to degradation and chemical change under the conditions it was used in this experiment. A portion of the hydrogen peroxide may have degraded in the process steps leading up to its introduction into the fermenters. Though we recognize this possibility, we infer a change in redox potential after the addition of of hydrogen peroxide to the fermenters as evidence that the hydrogen peroxide treatment did have an oxidizing effect on the culture, though possibly not as large as anticipated.

\section{Conclusions}

We examined C. thermocellum DSM 1313 redox metabolism by analyzing the transcriptional response to gradual addition of methyl viologen to steady-state cultures. Specific ethanol productivity increased steadily during methyl viologen addition, likely due to altered redox state, while $\mathrm{OD}_{600}$ dropped initially after methyl viologen addition and then recovered slightly and stabilized after $3000 \mathrm{~min}$ exposure. The redox potential of 
the fermentation was stable at $-500 \mathrm{mV}$ before methyl viologen addition and began dropping immediately after methyl viologen addition began and stabilized at $-550 \mathrm{mV}$ after approximately $100 \mathrm{~min}$. We observed a number of redox-active and ATP-requiring systems showing decreases in transcription as methyl viologen was added to chemostat cultures. Genes encoding sulfate transport and reduction, glutamate synthase-glutamine synthetases (the GS-GOGAT system), and portions of porphyrin biosynthesis showed differential expression in response to added methyl viologen, suggesting their involvement in mediating $C$. thermocellum redox homeostasis and energy metabolism. Genes encoding subunits and accessory proteins of the sole [NiFe] hydrogenase differentially expressed while those of [FeFe] hydrogenases did not. Other genes involved in transport, sporulation, and transposons also showed differential expression upon exposure to methyl viologen. This global profiling study provides gene targets for future studies to elucidate the relative contributions of prospective pathways for co-factor pool re-oxidation and $C$. thermocellum redox homeostasis.

\section{Methods}

\section{Strains, media, and materials}

Clostridium thermocellum DSM 1313 was obtained from the German Collection of Microorganisms and Cell Cultures (DSMZ) and grown in MTC medium essentially described previously [57]. Briefly, MTC was prepared as a mixture of five solutions and contained the following (final concentrations): Solution A: $1.1 \mathrm{~g} / \mathrm{L}$ cellobiose, $2 \mathrm{mg} / \mathrm{L}$ resazurin. Solution B: $2.12 \mathrm{~g} / \mathrm{L} \mathrm{C}_{6} \mathrm{H}_{7} \mathrm{~K}_{3} \mathrm{O}_{8}, 1.25 \mathrm{~g} / \mathrm{L}$ $\mathrm{C}_{6} \mathrm{H}_{8} \mathrm{O}_{7}-\mathrm{H}_{2} \mathrm{O}, 1 \mathrm{~g} / \mathrm{L} \quad \mathrm{Na}_{2} \mathrm{SO}_{4}, 1 \mathrm{~g} / \mathrm{L} \quad \mathrm{KH}_{2} \mathrm{PO}_{4}, 2.5 \mathrm{~g} / \mathrm{L}$ $\mathrm{NaHCO}_{3}$. Solution C: $1.5 \mathrm{~g} / \mathrm{L} \mathrm{NH}_{4} \mathrm{Cl}, 2 \mathrm{~g} / \mathrm{L} \mathrm{CH}_{4} \mathrm{~N}_{2} \mathrm{O}$. Solution D: $1 \mathrm{~g} / \mathrm{L} \quad \mathrm{MgCl}_{2}-6 \mathrm{H}_{2} \mathrm{O}, 0.2 \mathrm{~g} / \mathrm{L} \mathrm{CaCl}_{2}-2 \mathrm{H}_{2} \mathrm{O}$, $0.1 \mathrm{~g} / \mathrm{L} \mathrm{FeCl}_{2}-2 \mathrm{H}_{2} \mathrm{O}, 1 \mathrm{~g} / \mathrm{L} \mathrm{C}_{3} \mathrm{H}_{7} \mathrm{NO}_{2} \mathrm{~S}-\mathrm{HCl}-\mathrm{H}_{2} \mathrm{O}$. Solution E: $20 \mathrm{mg} / \mathrm{L}$ Pyridoxamine dihydrochloride, $4 \mathrm{mg} / \mathrm{L}$ P-aminobenzoic acid, $2 \mathrm{mg} / \mathrm{L}$ D-biotin, $2 \mathrm{mg} / \mathrm{L}$ vitamin B12. Solution F: $0.5 \mathrm{mg} / \mathrm{L} \mathrm{MnCl}_{2}-4 \mathrm{H}_{2} \mathrm{O}, 0.5 \mathrm{mg} / \mathrm{L} \mathrm{CoCl}_{2^{-}}$ $6 \mathrm{H}_{2} \mathrm{O}, 0.2 \mathrm{mg} / \mathrm{L} \mathrm{ZnCl}, 0.05 \mathrm{mg} / \mathrm{L} \mathrm{CuCl} 2-2 \mathrm{H}_{2} \mathrm{O}, 0.05 \mathrm{mg} / \mathrm{L}$ $\mathrm{H}_{3} \mathrm{BO}_{3}, 0.05 \mathrm{mg} / \mathrm{L} \mathrm{Na} \mathrm{NoO}_{4}-2 \mathrm{H}_{2} \mathrm{O}, 0.05 \mathrm{mg} / \mathrm{L} \mathrm{NiCl} 2^{-}$ $6 \mathrm{H}_{2} \mathrm{O}$. Media prepared for bottle-based batch fermentations contained $5 \mathrm{~g} / \mathrm{L}$ MOPS sodium salt. Media for chemostat cultivation did not contain MOPS sodium salt. All media were made anaerobic by sparging with $\mathrm{N}_{2}$ gas.

\section{Preliminary batch fermentations}

Clostridium thermocellum DSM 1313 was grown in MTC medium containing $1.1 \mathrm{~g} / \mathrm{L}$ cellobiose. Cultures were inoculated into hungate tubes containing $10 \mathrm{~mL}$ of medium and initial headspace of $10 \% \mathrm{CO}_{2}(\mathrm{v} / \mathrm{v}), 5 \% \mathrm{H}_{2}$ (v/v), and the balance $\mathrm{N}_{2}$. Methyl viologen was added to medium which was then pre-warmed overnight prior to inoculation. $\mathrm{H}_{2} \mathrm{O}_{2}$ was added to pre-warmed medium immediately prior to inoculation. Cultures were inoculated with $1 \mathrm{~mL}$ of overnight grown culture and growth was monitored using a Milton Roy Spectronic 21D UVVisible Spectrophotometer (Milton Roy Company). Soluble fermentation products were measured using HPLC (see HPLC analysis portion of methods) and headspace $\mathrm{H}_{2}$ \% was measured using an Agilent $6850 \mathrm{GC}$ equipped with a thermal conductivity detector (TCD) for $\mathrm{CO}_{2}$ and $\mathrm{H}_{2}$ quantification (Agilent Technologies, USA).

In preliminary batch fermentations, the end of fermentation was determined based on a decrease in culture $\mathrm{OD}_{600}$, common in $C$. thermocellum batch fermentations and thought to correspond with the onset of stationary phase. Samples for end-product determinations were collected immediately after the final OD600 reading was taken. End-products were normalized to the average maximum OD600 achieved during batch fermentation.

\section{Chemostat growth and stress application}

Clostridium thermocellum DSM 1313 was grown at $55^{\circ} \mathrm{C}$ in duplicate $1 \mathrm{~L}$ (total vessel capacity $1.3 \mathrm{~L}$ ) chemostat cultures using water-jacketed BioFlo110 bioreactors (New Brunswick Scientific, Edison, NJ, USA) with $1.1 \mathrm{~g} / \mathrm{L}$ cellobiose as the carbon source in MTC medium, which was fed at a dilution rate of $0.1 \mathrm{~h}^{-1}$. Temperature, $\mathrm{pH}$, and agitation speed were monitored and controlled during fermentation. Culture $\mathrm{pH}$ was monitored using $\mathrm{pH}$ electrodes (Mettler-Toledo, Columbus, OH, USA) and the $\mathrm{pH}$ control set point was maintained at 7.0 by automatic titration with $3 \mathrm{~N} \mathrm{KOH}$. Fermenter redox potential was measured using DPAS K8S 325 combination redox probes (Mettler-Toledo) attached to an independent signal transducer and readout (Sartorious Stedim Biotech, model \# 8890354). Redox probes were checked for accuracy using new redox probe calibration solutions (Ricca Chemical Company catalog \#4330-16, Ricca Chemical Company catalog \#9880-16, Orion Application Solution \# 967901). Agitation was supplied by a central impeller with two paddled rotors maintained at $200 \mathrm{rpm}$ and no additional baffles. Culture turbidity was measured taking optical density readings at $600 \mathrm{~nm}$ using a Genesys 20 spectrophotometer (Thermo Fisher Scientific Inc., Waltham, MA, USA).

Fermenters were inoculated using $100 \mathrm{~mL}$ of overnight cultures into $900 \mathrm{~mL}$ of neutral MTC previously sparged overnight with $\mathrm{N}_{2}$ gas. After inoculation, $\mathrm{N}_{2}$ sparging was stopped and for the duration of chemostat growth $\mathrm{N}_{2}$ was flushed into the fermenter headspace. Chemostat steady-state growth was defined as being at least $50 \mathrm{~h}$ of continuous growth during which the culture $\mathrm{OD}_{600}$ fluctuated less than $5 \%$. Individual chemical stressors were added to medium feed carboys at final concentrations of $10 \mathrm{mg} / \mathrm{L} \mathrm{H}_{2} \mathrm{O}_{2}$ or $150 \mathrm{mg} / \mathrm{L}$ methyl viologen and fed 
into the reactors with medium feed over $60 \mathrm{~h}$ (6 retention times). Chemostat methyl viologen and $\mathrm{H}_{2} \mathrm{O}_{2}$ concentrations were selected based on preliminary batch experiments (Additional files 1, 3, respectively) and in each case, culture growth rates were not impacted by greater than $50 \%$ and final fermentation product concentrations (normalized to maximum $\mathrm{OD}_{600}$ ) changed by $>20 \%$. Upon completion of each chemostat stress treatment, a $500 \mathrm{~mL}$ volume was withdrawn from each vessel and then reactors were re-filled in fed-batch mode to $1 \mathrm{~L}$ with only MTC medium and then chemostat operation was resumed. Remaining stressor was allowed to wash out for another $50 \mathrm{~h}$ ( 5 retention times) and a re-equilibration period of $50 \mathrm{~h}$ followed before the next stress application. Methyl viologen and hydrogen peroxide concentrations or chemical stability were not measured or assayed directly in the fermenters or feed carboys. Redox potential was measured and recorded in the fermenters to ensure stress chemical additions were changing the fermentation redox potential and the overall redox environment. Chemostat culture integrity was checked periodically by microscopy and PCR amplification and sequencing of the 16S rRNA gene using forward sequencing primer AGAGTTTGATCCTGGCTCAG and reverse sequencing primer GGGCGGTGTGTACAAGG. Biofilm growth or excessive frothing was not observed or mitigated during chemostat growth.

\section{Fermentation product analysis using high-performance liquid chromatography (HPLC)}

HPLC samples were collected by centrifugation at $13,000 \mathrm{rpm}$ in a microcentrifuge and passed through a $0.22 \mu \mathrm{m}$ filter, acidified with $11.6 \mathrm{mN} \mathrm{H}_{2} \mathrm{SO}_{4}$ and stored at $4{ }^{\circ} \mathrm{C}$ until analyzed using a LaChrom Elite System (Hitachi High Technologies America, Inc., CA, USA) fitted with a Aminex HPX 87H HPLC column $(300 \times 7.8 \mathrm{~mm})$ (BioRad, Hercules, Dallas, TX, USA) kept at $60^{\circ} \mathrm{C}$ and using a mobile phase of $5 \mathrm{mM} \mathrm{H}_{2} \mathrm{SO}_{4}$ with a flow rate of $0.5 \mathrm{~mL} /$ min for 35 min per sample. Eluted compounds were detected by a refractive index detector (Model L-2490) and quantified via retention time and peak areas. Standard curves were used to quantify peak areas from samples and each sample was injected at least twice.

\section{RNA isolation, cDNA synthesis, microarray hybridization, and data analysis}

Briefly, $50 \mathrm{~mL}$ aliquots from chemostat cultures were harvested by centrifugation $\left(8000 \mathrm{rpm}, 4{ }^{\circ} \mathrm{C}, 4 \mathrm{~min}\right.$ using a Sorvall RC5C plus centrifuge), the supernatant decanted and removed and the remaining pellets were quickly frozen in liquid nitrogen and stored at $-80{ }^{\circ} \mathrm{C}$. Frozen cell pellets were resuspended in TRIzol reagent (Invitrogen, Carlsbad, CA, USA), lysed by adding $1.5 \mathrm{~mL}$ of cell
pellet/TRIzol mixture to $2 \mathrm{~mL}$ screw top tubes containing $800 \mathrm{mg}$ of ashed glass beads (\#11079101, Biospec products, Bartlesville, OK, USA) followed by bead beating for three $20 \mathrm{~s}$ cycles at $6500 \mathrm{rpm}$ using a Precellys-24 (Bertin Technologies, Montigny-le-Bretonneux, France). Total cellular RNA was purified using a QIAGEN RNeasy Mini kit according to the manufacturer's instructions, which included an on column RNase-free DNase treatment to digest residual chromosomal DNA. RNA was quantified using a NanoDrop ND-1000 spectrophotometer (NanoDrop Technologies, DE, USA) and a Bioanalyzer 2100 (Agilent Technologies Inc., CA, USA). Double-strand (ds) cDNA was generated from purified RNA using a dscDNA synthesis kit (Invitrogen Life Technologies, NY, USA), which was subsequently labeled, hybridized, and washed according to the NimbleGen (Roche NimbleGen, IN, USA) protocols as described previously [16]. C. thermocellum transcriptome profiles were generated using an established C. thermocellum strain 27405 DNA microarray platform that contains 5-7 unique probes per gene and with three technical replicates for each unique probe, as described previously [14-16]. C. thermocellum strains DSM1313 and ATCC27045 are closely related; with average nucleotide identities (ANIs) of 99.6 and $99.3 \%$ in reciprocal genome comparisons, indicating the strains are very closely related. Strain ATCC 27405 has a putative high-affinity phosphate transport system that DSM1313 lacks [16] and ATCC 27405 contains additional prophage and restriction-modification sequences [55]; hence the ATCC27405 DNA microarray was suitable to assess C. thermocellum strain DSM1313. Hybridizations were conducted using a 12-bay hybridization station (BioMicro Systems, Inc., UT, USA). Microarrays were dried and then scanned with a Surescan high-resolution DNA microarray scanner $(5 \mu \mathrm{m})$ (Agilent Technologies, CA, USA), and the images were quantified using NimbleScan software (Roche NimbleGen). Raw data was $\log _{2}$ transformed and imported into the statistical analysis software JMP Genomics 6.0 software (SAS Institute, NC, USA). Data were normalized together using a single round of the LOWESS normalization algorithm within JMP Genomics. Distribution analyses were conducted before and after normalization as a quality control step. An ANOVA was performed in JMP Genomics to determine differential expression levels between untreated, equilibrated conditions immediately prior to stressor exposure and timepoints during stressor exposure using the false discovery rate (FDR) testing method $(p<0.05)$ and array slide used as a random variable. Microarray data have been deposited in the NCBI GEO database [GSE71465]. The Pathway Tools software [58] was used to overlay differential expression data onto a $C$. thermocellum metabolic map. The 'Omics Viewer' function 
within the software was used along with the curated genome-inferred metabolic model of $C$. thermocellum as provided in the Pathway Tools Pathway/Genome Database. $\log 2$ normalized differential transcription as computed by differential expression analysis done using JMP genomics was imported and used to overlay the data.

\section{Microarray validation using real-time quantitative-PCR (RT-qPCR)}

Microarray data were validated using RT-qPCR, as described previously [16]. Oligonucleotide sequences of the primers targeting five genes are listed in Additional file 4. Correlations between differential expression values obtained by RT-qPCR analysis and microarray analysis gave an $R^{2}$ value of 0.94 indicating expression values obtained by microarray analysis are of good quality.

\section{Methyl viologen incubation experiment}

Clostridium thermocellum DSM 1313 cells prepared under different conditions (washed and resuspended in distilled water, actively growing in medium, stationary phase in medium, autoclave killed, grown with and without resazurin) were incubated in $150 \mathrm{mg} / \mathrm{L}$ methyl viologen (Sigma Aldrich) to determine the origin of the reductant being used to reduce methyl viologen by growing cultures. To prepare live cell aliquots containing medium, $1 \mathrm{~mL}$ of $\log$ phase and stationary phase C. thermocellum DSM 1313 cells were aliquoted anaerobically into $1.5 \mathrm{~mL}$ centrifuge tubes. To prepare live cell aliquots without medium, $1 \mathrm{~mL}$ of live cells (both log phase and stationary phase) were aliquoted and washed three times with and resuspended in anaerobic distilled water. To prepare spent medium aliquots, $1 \mathrm{~mL}$ of $\log$ phase cells were aliquoted, centrifuged at 14,000 rpm for $3 \mathrm{~min}$, and filtered with a 0.22 -micron syringe filter. All preparations were conducted in duplicate. Methyl viologen was added to all preparations to a final concentration of $150 \mathrm{mg} / \mathrm{L}$, incubated anaerobically at $55{ }^{\circ} \mathrm{C}$ for five days and visually inspected for blue coloration as an indication of reduced methyl viologen.

\section{Additional files}

Additional file 1. Batch fermentation performance under methyl viologen and hydrogen peroxide initial loadings.

Additional file 2. Calculated differential expression and adjusted $p$ values for genes showing significant (adjusted $p$ value $<0.05$ ) differential expression during at least one timepoint of either methyl viologen or hydrogen peroxide exposure.

Additional file 3. (A) Adjusted $\mathrm{OD}_{600}$ of batch cultures grown at various initial hydrogen peroxide concentrations. Cultures were grown in MTC media containing $1.1 \mathrm{~g} / \mathrm{L}$ cellobiose; (B) Chemostat $\mathrm{OD}_{600}$ and measured redox potential before, during and after hydrogen peroxide addition; (C) Detailed view of boxed region indicated in panel (B).

Additional file 4. qPCR validation of expression differences of selected genes of interest.

\section{Abbreviation}

CBP: Consolidated BioProcessing.

\section{Authors' contributions}

$\mathrm{KS}, \mathrm{BHD}$, and SDB designed the experiments. KS and MR conducted growth studies and fermentation product analysis. DMK generated DNA microarray data. KS, CMW, BHD, and SDB analyzed the data and wrote the manuscript. $M R$, TR, and DMK provided preliminary critical review and suggested revisions to the manuscript prior to submission. All authors read and approved the final manuscript.

\section{Author details}

${ }^{1}$ Bredesen Center for Interdisciplinary Research and Graduate Education, University of Tennessee, Knoxville, TN 37996, USA. ${ }^{2}$ BioEnergy Science Center, Oak Ridge National Laboratory, Oak Ridge, TN 37831, USA. ${ }^{3}$ Department of Chemical and Biomolecular Engineering, University of Tennessee, Knoxville, TN 37996, USA. ${ }^{4}$ Biosciences Division, Oak Ridge National Laboratory, Oak Ridge, TN 37831, USA.

\section{Acknowledgements}

We thank Richard Sparling (University of Manitoba) for helpful discussions. This work is sponsored by the BioEnergy Science Center, which is a US Department of Energy Bioenergy Research Center supported by the Office of Biological and Environmental Research in the DOE Office of Science. This manuscript has been authored by UT-Battelle, LLC, under Contract no. DE-AC05-00OR22725 with the US Department of Energy.

This manuscript has been authored by UT-Battelle, LLC under Contract no. DE-AC05-00OR22725 with the US Department of Energy. The United States Government retains and the publisher, by accepting the article for publication, acknowledges that the United States Government retains a nonexclusive, paid-up, irrevocable, world-wide license to publish or reproduce the published form of this manuscript, or allow others to do so, for United States Government purposes. The Department of Energy will provide public access to these results of federally sponsored research in accordance with the DOE Public Access Plan (http://energy.gov/downloads/doe-public-access-plan).

\section{Competing interests}

The authors declare that they have no competing interests.

Received: 19 August 2015 Accepted: 24 November 2015

Published online: 12 December 2015

\section{References}

1. Blumer-Schuette SE, Brown SD, Sander KB, Bayer EA, Kataeva I, Zurawski $J \mathrm{~V}$, et al. Thermophilic lignocellulose deconstruction. FEMS Microbiol Rev. 2013;38:393-448. doi:10.1111/1574-6976.12044.

2. Lynd LR, ZyI WHV, McBride JE, Laser M. Consolidated bioprocessing of cellulosic biomass: an update. Curr Opin Biotechnol. 2005;16(5):577-83. doi:10.1016/j.copbio.2005.08.009.

3. Shoham Y, Lamed R, Bayer EA. The cellulosome concept as an efficient microbial strategy for the degradation of insoluble polysaccharides. Trends Microbiol. 1999;7(7):275-81.

4. Lynd LR, Grethlein HE, Wolkin RH. Fermentation of cellulosic substrates in batch and continuous culture by Clostridium thermocellum. Appl Environ Microbiol. 1989;55(12):3131-9.

5. Biswas R, Zheng T, Olson D, Lynd LR, Guss A. Elimination of hydrogenase active site assembly blocks $\mathrm{H}_{2}$ production and increases ethanol yield in Clostridium thermocellum. Biotechnol Biofuels. 2015;8(1):20.

6. Argyros DA, Tripathi SA, Barrett TF, Rogers SR, Feinberg LF, Olson DG, et al. High ethanol titers from cellulose using metabolically engineered thermophilic, anaerobic microbes. Appl Environ Microbiol. 2011;77:8288-94. doi:10.1128/aem.00646-11.

7. Tripathi SA, Olson DG, Argyros DA, Miller BB, Barrett TF, Murphy DM, et al Development of pyrF-based genetic system for targeted gene deletion in Clostridium thermocellum and creation of a pta mutant. Appl Environ Microbiol. 2010;76:6591-9. 
8. Yee KL, Rodriguez M Jr, Thompson OA, Fu C, Wang ZY, Davison BH, et al. Consolidated bioprocessing of transgenic switchgrass by an engineered and evolved Clostridium thermocellum strain. Biotechnol Biofuels. 2014;7:75. doi:10.1186/1754-6834-7-75.

9. Deng Y, Olson DG, Zhou J, Herring CD, Joe Shaw A, Lynd LR. Redirecting carbon flux through exogenous pyruvate kinase to achieve high ethanol yields in Clostridium thermocellum. Metabolic Eng. 2013;15:151-8. doi:10.1016/j.ymben.2012.11.006.

10. Holwerda E, Thorne P, Olson D, Amador-Noguez D, Engle N, Tschaplinski T, et al. The exometabolome of Clostridium thermocellum reveals overflow metabolism at high cellulose loading. Biotechnol Biofuels. 2014;7(1):155

11. van der Veen D, Lo J, Brown SD, Johnson CM, Tschaplinski TJ, Martin M, et al. Characterization of Clostridium thermocellum strains with disrupted fermentation end-product pathways. J Ind Microbiol Biotechnol. 2013;40:725-34. doi:10.1007/s10295-013-1275-5.

12. RydzakT, Levin DB, Cicek N, Sparling R. End-product induced metabolic shifts in Clostridium thermocellum ATCC 27405. Appl Microbiol Biotechnol. 2011;92(1):199-209. doi:10.1007/s00253-011-3511-0.

13. Rydzak T, Grigoryan M, Cunningham Z, Krokhin O, Ezzati P, Cicek N, et al. Insights into electron flux through manipulation of fermentation conditions and assessment of protein expression profiles in Clostridium thermocellum. Appl Microbiol Biotechnol. 2014;98(14):6497-510. doi:10.1007/ s00253-014-5798-0.

14. Wilson CM, Rodriguez M Jr, Johnson CM, Martin SL, Chu TM, Wolfinger RD, et al. Global transcriptome analysis of Clostridium thermocellum ATCC 27405 during growth on dilute acid pretreated Populus and switchgrass. Biotechnol Biofuels. 2013;6:179.

15. Wilson CM, Yang S, Rodriguez M Jr, Ma Q, Johnson CM, Dice L, et al. Clostridium thermocellum transcriptomic profiles after exposure to furfural or heat stress. Biotechnol Biofuels. 2013;6:131.

16. Yang S, Giannone RJ, Dice L, Yang ZK, Engle NL, Tschaplinski TJ, et al. Clostridium thermocellum ATCC27405 transcriptomic, metabolomic and proteomic profiles after ethanol stress. BMC Genom. 2012;13(1):336. doi:10.1186/1471-2164-13-336.

17. Linville JL, Rodriguez M, Brown SD, Mielenz JR, Cox CD. Transcriptomic analysis of Clostridium thermocellum Populus hydrolysate-tolerant mutant strain shows increased cellular efficiency in response to Populus hydrolysate compared to the wild type strain. BMC Microbiol. 2014;14(1):215. doi:10.1186/s12866-014-0215-5.

18. Beliaev AS, Klingeman DM, Klappenbach JA, Wu L, Romine MF, Tiedje JM, et al. Global transcriptome analysis of Shewanella oneidensis MR-1 exposed to different terminal electron acceptors. J Bacteriol. 2005;187(20):7138-45. doi:10.1128/jb.187.20.7138-7145.2005.

19. Honicke D, Janssen H, Grimmler C, Ehrenreich A, Lütke-Eversloh T. Global transcriptional changes of Clostridium acetobutylicum cultures with increased butanol: acetone ratios. New Biotechnol. 2012;29(4):485-93.

20. Ravcheev DA, Li X, Latif H, Zengler K, Leyn SA, Korostelev YD, et al. Transcriptional regulation of central carbon and energy metabolism in bacteria by redox-responsive repressor Rex. J Bacteriol. 2012;194:1145-57. doi:10.1128/jb.06412-11.

21. Christensen GA, Zane GM, Kazakov AE, Li X, Rodionov DA, Novichkov PS, et al. Rex (encoded by DVU_0916) in Desulfovibrio vulgaris Hildenborough is a repressor of sulfate adenylyl transferase and is Regulated by NADH.J Bacteriol. 2015;197:29-39. doi:10.1128/jb.02083-14.

22. Wietzke $M, B a h l H$. The redox-sensing protein Rex, a transcriptional regulator of solventogenesis in Clostridium acetobutylicum. Appl Microbiol Biotechnol. 2012;96(3):749-61. doi:10.1007/s00253-012-4112-2.

23. Korte H, Fels SR, Christensen GA, Price MN, Kuehl JV, Zane GM, et al. Genetic basis for nitrate resistance in Desulfovibrio strains. Front Microbiol. 2014;5:153. doi:10.3389/fmicb.2014.00153.

24. Desvaux M. Unravelling carbon metabolism in anaerobic cellulolytic bacteria. Biotechnol Prog. 2006;22(5):1229-38. doi:10.1021/bp060016e.

25. Payot S, Guedon E, Cailliez C, Gelhaye E, Petitdemange H. Metabolism of cellobiose by Clostridium cellulolyticum growing in continuous culture: evidence for decreased NADH reoxidation as a factor limiting growth. Microbiol. 1998;144(2):375-84. doi:10.1099/00221287-144-2-375.

26. Li H-F, Knutson BL, Nokes SE, Lynn BC, Flythe MD. Metabolic control of Clostridium thermocellum via inhibition of hydrogenase activity and the glucose transport rate. Appl Microbiol Biotechnol. 2012;93(4):1777-84. doi:10.1007/s00253-011-3812-3.
27. Reimann A, Biebl H, Deckwer WD. Influence of iron, phosphate and methyl viologen on glycerol fermentation of Clostridium butyricum. Appl Microbiol Biotechnol. 1996;45(1-2):47-50. doi:10.1007/s002530050647.

28. Rao G, Mutharasan R. Alcohol production by Clostridium acetobutylicum induced by methyl viologen. Biotechnol Lett. 1986;8(12):893-6. doi:10.1007/bf01078655.

29. Rao G, Mutharasan R. Altered electron flow in continuous cultures of Clostridium acetobutylicum induced by viologen dyes. Appl Environ Microbiol. 1987;53(6):1232-5.

30. Thorneley RNF. A convenient electrochemical preparation of reduced methyl viologen and a kinetic study of the reaction with oxygen using an anaerobic stopped-flow apparatus. Biochim Biophys Acta (BBA) Bioenerg. 1974;333(3):487-96. doi:10.1016/0005-2728(74)90133-9.

31. Tsibris JCM, Woody RW. Structural studies of iron-sulfur proteins. Coordination Chem Rev. 1970;5(4):417-58. doi:10.1016/S0010-8545(00)80100-9.

32. Ware DA. Nitrogenase of Klebsiella pneumoniae: interaction with viologen dyes as measured by acetylene reduction. Biochem J. 1972;130(1):301-2.

33. Guerrero MG, MaVega J, Leadbener E, Losada M. Preparation and characterization of a soluble nitrate reductase from Azotobacter chroococcum. Arch Mikrobiol. 1973;91:287-304.

34. Dietrich LEP, Price-Whelan A, Petersen A, Whiteley M, Newman DK. The phenazine pyocyanin is a terminal signalling factor in the quorum sensing network of Pseudomonas aeruginosa. Mol Microbiol. 2006;61(5):1308-21. doi:10.1111/j.1365-2958.2006.05306.x.

35. Gu M, Imlay JA. The SoxRS response of Escherichia coli is directly activated by redox-cycling drugs rather than by superoxide. Mol Microbiol. 2011;79(5):1136-50. doi:10.1111/j.1365-2958.2010.07520.x.

36. Taillefer M, Rydzak T, Levin DB, Oresnik IJ, Sparling R. Reassessment of the transhydrogenase 'malate shunt' in Clostridium thermocellum ATCC 27405 through kinetic characterization of malic enzyme and malate dehydrogenase. Appl Environ Microbiol. 2015;81:2423-32. doi:10.1128/ aem.03360-14.

37. Bogdahn M, Kleiner D. Inorganic nitrogen metabolism in two cellulosedegrading Clostridia. Arch Microbiol. 1986;145(2):159-61. doi:10.1007/ bf00446774.

38. Pengpeng W, Tan Z. Ammonia assimilation in rumen bacteria: a review. Anim Biotechnol. 2013;24(2):107-28. doi:10.1080/10495398.2012.756402.

39. Fedorova KP, Tarasov NV, Khalitova AV, Iljinskaya ON, Barabanshchikov $B I$, Kayumov AR. The role of AmtB, GInK and glutamine synthetase in regulation of of transcription factor TnrA in Bacillus subtilis. Cell Tiss Biol. 2013;7(3):297-301. doi:10.1134/s1990519x13020041.

40. Fierro-Monti IP, Reid SJ, Woods DR. Differential expression of a Clostridium acetobutylicum antisense RNA: implications for regulation of glutamine synthetase. J Bacteriol. 1992;174(23):7642-7.

41. Kridelbaugh DM, Nelson J, Engle NL, Tschaplinski TJ, Graham DE. Nitrogen and sulfur requirements for Clostridium thermocellum and Caldicellulosiruptor bescii on cellulosic substrates in minimal nutrient media. Bioresour Technol. 2013;130:125-35. doi:10.1016/j.biortech.2012.12.006.

42. Schobert M, Jahn D. Regulation of heme biosynthesis in non-phototrophic bacteria. J Mol Microbiol Biotechnol. 2002;4(3):287-94.

43. Hungerer C, Troup B, Römling U, Jahn D. Regulation of the hemA gene during 5-aminolevulinic acid formation in Pseudomonas aeruginosa. J Bacteriol. 1995;177(6):1435-43.

44. Erbes DL, Burris RH. The kinetics of methyl viologen oxidation and reduction by the hydrogenase from Clostridium pasteurianum. Biochim Biophys Acta (BBA) Enzymol. 1978;525(1):45-54. doi:10.1016/0005-2744(78)90198-5.

45. Okura I, Nakamura K-I, Nakamura S. Kinetics of methyl viologen reduction by hydrogen catalyzed by hydrogenase from Desulfovibrio vulgaris. J Inorg Biochem. 1981;14(2):155-61. doi:10.1016/S0162-0134(00)80036-7.

46. RydzakT, McQueen P, Krokhin O, Spicer V, Ezzati P, Dwivedi R, et al. Proteomic analysis of Clostridium thermocellum core metabolism: relative protein expression profiles and growth phase-dependent changes in protein expression. BMC Microbiol. 2012;12(1):214.

47. Rydzak T, Levin DB, Cicek N, Sparling R. Growth phase-dependant enzyme profile of pyruvate catabolism and end-product formation in Clostridium thermocellum ATCC 27405. J Biotechnol. 2009;140(3-4):16975. doi:10.1016/j.jbiotec.2009.01.022.

48. Carere C, Rydzak T, Cicek N, Levin D, Sparling R. Role of transcription and enzyme activities in redistribution of carbon and electron flux in response to $\mathrm{N}_{2}$ and $\mathrm{H}_{2}$ sparging of open-batch cultures of Clostridium 
thermocellum ATCC 27405. Appl Microbiol Biotechnol. 2014;98:2829-40. doi:10.1007/s00253-013-5500-y.

49. Carere CR, Kalia V, Sparling R, Cicek N, Levin DB. Pyruvate catabolism and hydrogen synthesis pathway genes of Clostridium thermocelIum ATCC 27405. Ind J Microbiol. 2008;48(2):252-66. doi:10.1007/ s12088-008-0036-z.

50. Vignais PM. Regulation of hydrogenase gene expression. In: Hunter CN, Daldal F, Thurnauer M, Beatty JT, editors. The purple phototrophic bacteria. Advances in photosynthesis and respiration. The Netherlands: Springer; 2009. p. 743-57.

51. Rey FE, Oda Y, Harwood CS. Regulation of uptake hydrogenase and effects of hydrogen utilization on gene expression in Rhodopseudomonas palustris. J Bacteriol. 2006;188(17):6143-52. doi:10.1128/jb.00381-06.

52. Mearls EB, Izquierdo JA, Lynd LR. Formation and characterization of non-growth states in Clostridium thermocellum: spores and L-forms. BMC Microbiol. 2012;12(1):180.

53. Mearls EB, Lynd LR. The identification of four histidine kinases that influence sporulation in Clostridium thermocellum. Anaerobe. 2014;28:109-19. doi:10.1016/j.anaerobe.2014.06.004.

54. Zverlov VV, Klupp M, Krauss J, Schwarz WH. Mutations in the scaffoldin gene, cipA, of Clostridium thermocellum with impaired cellulosome formation and cellulose hydrolysis: insertions of a new transposable element,
IS1447, and implications for cellulase synergism on crystalline cellulose. J Bacteriol. 2008;190(12):4321-7. doi:10.1128/jb.00097-08.

55. Brown SD, Nagaraju S, Utturkar SM, De Tissera S, Segovia S, Mitchell W, et al. Comparison of single-molecule sequencing and hybrid approaches for finishing the genome of Clostridium autoethanogenum and analysis of CRISPR systems in industrial relevant Clostridia. Biotechnol Biofuels. 2014;7:40.

56. Ritz D, Beckwith J. Roles of thiol-redox pathways in bacteria. Ann Rev Microbiol. 2001;55(1):21-48. doi:10.1146/annurev.micro.55.1.21.

57. Zhang Y, Lynd LR. Quantification of cell and cellulase mass concentrations during anaerobic cellulose fermentation: development of an enzyme-linked immunosorbent assay-based method with application to Clostridium thermocellum batch cultures. Anal Chem. 2002;75(2):219-27. doi:10.1021/ac020271n.

58. Karp PD, Paley SM, Krummenacker M, Latendresse M, Dale JM, Lee TJ, et al. Pathway tools version 13.0: integrated software for pathway/genome informatics and systems biology. Brief Bioinform. 2010;11(1):40-79.

\section{Submit your next manuscript to BioMed Central and we will help you at every step:}

- We accept pre-submission inquiries

- Our selector tool helps you to find the most relevant journal

- We provide round the clock customer support

- Convenient online submission

- Thorough peer review

- Inclusion in PubMed and all major indexing services

- Maximum visibility for your research

Submit your manuscript at www.biomedcentral.com/submit 